\title{
APPLICATION OF THE SWAT MODEL IN THE PINIOS RIVER BASIN UNDER DIFFERENT LAND-USE SCENARIOS
}

\section{PIKOUNIS M. \\ VARANOU E. \\ BALTAS E. \\ DASSAKLIS A. \\ MIMIKOU M.*}

Selected from papers presented at the $8^{\text {th }}$ International Conference on Environmental Science and Technology,

8 - 10 September 2003, Lemnos, Greece.
National Technical University of Athens,

Faculty of Civil Engineering,

Department of Water Resources,

Hydraulic and Maritime Engineering

*to whom all correspondence should be addressed:

fax: $+(30) 2107722879$

e-mail : mimikou@chi.civil.ntua.gr

\section{ABSTRACT}

This paper investigates the hydrological effects of specific land use changes in a catchment of the river Pinios in Thessaly (Ali Efenti catchment), through the application of the Soil and Water Assessment Tool (SWAT) on a monthly time step. The model's calibration efficiency is verified by comparing the simulated and observed discharge time series at the outlet of the watershed, where long series of hydrometrical data exist. The model is used to simulate the main components of the hydrologic cycle, in order to study the effects of land use changes. Three land use change scenarios are examined, namely (A) expansion of agricultural land, (B) complete deforestation of the Trikala sub-basin and (C) expansion of urban areas in the Trikala sub-basin. All three scenarios resulted in an increase in discharge during wet months and a decrease during dry periods. The deforestation scenario was the one that resulted in the greatest modification of total monthly runoff.

KEYWORDS: hydrologic models, Soil and Water Assessment Tool, land use changes

\section{INTRODUCTION}

Land use changes which are biophysically or, more commonly in the last years, artificially based (Skole and Tucker, 1993), often have significant effects on the surrounding environment and consequently on the hydrological cycle. Understanding land use change in relation to its driving factors provides essential information for land use planning and sustainable management of resources (Verburg et al., 1999). Although the empirical knowledge of the consequences of land use changes is obvious, it is often very difficult to explicitly quantify these consequences.

This study presents a method for quantifying the impacts from specific land-use changes on the runoff of catchments, by examining the case study of a certain basin of the river Pinios in Thessaly, Greece. The method combines a software package that simulates the hydrological cycle with one that sets up the land use change scenarios, thus providing a sensitivity analysis of runoff to certain land use changes. The water cycle is simulated 
with the use of the Soil and Water Assessment Tool (SWAT). This is a hydrological model that requires, among other input data, the land uses of the inspected areas, in the form of a digital map. The study focuses on the calculation of the total streamflow of the river, and the results are compared to the observed values in the outlet of the basin, by estimating the Nash \& Sutcliffe coefficient, as well as other indexes. In order to examine the sensitivity of the model to land-use data, a detailed description of the existing land uses in the area is given, and the calibration results are compared to previous studies, where less detailed land use data were used.

The land use change scenarios were built using a beta version of Lademo (Land use Development Model), a prototype procedure created by the Potsdam Institute in Germany (www.potsdampik.de), in the framework of the EUROTAS project (funded under the $4^{\text {th }}$ Environment framework ENV 63/846). The model was presented at the European Conference on Advances in Flood Research, held in Potsdam, Germany, on November 2000.

The procedure gives the option of specifying the percentage of change for a certain land use, from one type to another (or others). The current state of the land use pattern in Pinios basin was introduced into the Lademo procedure, in the form of a digital map, and three different scenarios (three new digital maps) were built. The maps were consequently introduced in SWAT as input data and the new discharge outputs were calculated. The river discharge results for each scenario were compared to those of the current state, thus providing with an estimate for the percentage of change in the total discharge caused by each scenario, on a monthly time step. All software used operates under the Arcview GIS environment (Blackland Research Center, 1999).

\section{DESCRIPTION OF THE SWAT MODEL}

The Soil and Water Assessment Tool is a river basin model that was developed for the USDA Agricultural Research Service, by Blackland Research Center in Texas (http://www.brc.tamus.edu/blackland/). The SWAT model is a widely known tool that has been used in several cases world-wide. SWAT has the ability to predict the impact of land management practices on water, sediment yield and agricultural chemical yield in large complex water- sheds (Neitsch et al., 1999). The present study focuses only on the hydrological component of the model. What distinguishes SWAT from common techniques used to estimate runoff is that it is a physical model. The model takes into account such data as climate, soil properties, topography, land cover and management, and produces outputs with the use of common hydrological equations.

Apart from the ability to take into account land use and soil data, SWAT differs from other physical models in its ability to separate the watershed into sub-basins and Hydrologic Response Units (HRUs). The main basin is divided into smaller ones, by selecting points on the stream network that act as outlets. In this way, the model can provide output data, such as discharge, at specific points of the river network. The partitioning of the basin or the subbasins in HRUs has the meaning of dividing the watershed into no more than 100 different areas, which have the same properties regarding land use and soil. The equations are applied in each HRU separately and surface runoff and ground water flow are routed to neighbouring HRUs, up to the outlet of the basin (Arnold et al., 1999). The hydrologic component of SWAT is based on the following water balance equation:

$$
S W_{t}=S W+\sum_{i=1}^{t}\left(R_{i}-Q_{i}-E T_{i}-P_{i}-Q R_{i}\right)
$$

where: $\mathrm{SW}_{\mathrm{t}}$ is the final soil water content $(\mathrm{mm})$, SW is the water content available for plant uptake, defined as the initial soil water content minus the permanent wilting point water content $(\mathrm{mm}), \mathrm{t}$ is time in days, $\mathrm{R}$ is rainfall $(\mathrm{mm}), \mathrm{Q}_{\mathrm{i}}$ is surface runoff $(\mathrm{mm}), \mathrm{ET}_{i}$ is evapotranspiration $(\mathrm{mm}), \mathrm{P}_{\mathrm{i}}$ is percolation $(\mathrm{mm})$ and $\mathrm{QR}_{\mathrm{i}}$ is return flow. SWAT incorporates some of the most common hydrological equations for the simulation of flow. For the accurate implementation of these equations, detailed input data are needed. Of significant value to the simulation are the digital elevation model (DEM) of the watershed, the soil and land use data and the climatic data of the area. The importance of land uses in the operation of the model lies mainly in the computation of surface runoff with the help of the SCS curve (Arnold et al., 1999). The model includes in its database 102 different land use types, with each 
one assigned to a CNII value (Curve Number for hydrological condition II). The user is required to link each of the land uses that appear in the watershed, to the ones that the model can identify. The success of the simulation depends highly on the accurate assignment of land uses.

\section{STUDY AREA AND DATA USED}

\section{Study area}

The model is implemented in the watershed of Pinios River, in the outlet of Ali Efenti. The catchment has an area of $2976 \mathrm{~km}^{2}$ and is located in the Thessaly plain, in central Greece, between the parallels 39.30' South to 40.00' North and 21.20' West to 22.10' East (Mimikou, 1999, Varanou et al., 2001). The mean elevation of the basin is 540 $\mathrm{m}$, with mountainous landscape appearing in the north and west part and large plains in the central and southeast, as shown in Figure 1.

\section{Land use data}

The land use patterns were derived from the European project Corine, by which different types of land cover throughout countries of Europe were charted. These data were received in the form of a digital map, with polygons representing different records of uses (Varanou et al., 2000). Processing of the data was done with the use of Arcview GIS, by categorising known uses into larger groups, while unknown ones were inte- grated into the known. The process concluded with the charting of 21 different types of land cover, which were subsequently cross-referenced to the appropriate uses included in the database of the SWAT model. A total of 10 different SWAT land uses were finally chosen.

\section{Soil data}

The soil data were acquired from the Greek Ministry of Agriculture. The 15 different types of soil and rock that appear in the basin were introduced into SWAT in the form of a digital map. A series of attributes was assigned to each type of soil, namely depth, saturated hydraulic conductivity and content of clay, silt and sand. The soil pattern of the basin is of essential importance to the model, since in combination with the land uses determines the HRUs of the catchment and, to a large extent, also determines groundwater flow.

\section{Hydrometeorological data}

The climatic and streamflow data were derived from 35 hydrometeorological stations located in the wider area of the basin under study. Climatic data refer to daily precipitation and temperature, for the period from 1970 to 1996. Additionally, the average mean monthly values of wind speed, solar radiation and relative humidity, for the same period, are also required for the calculation of evapotranspiration. Daily streamflow data in the

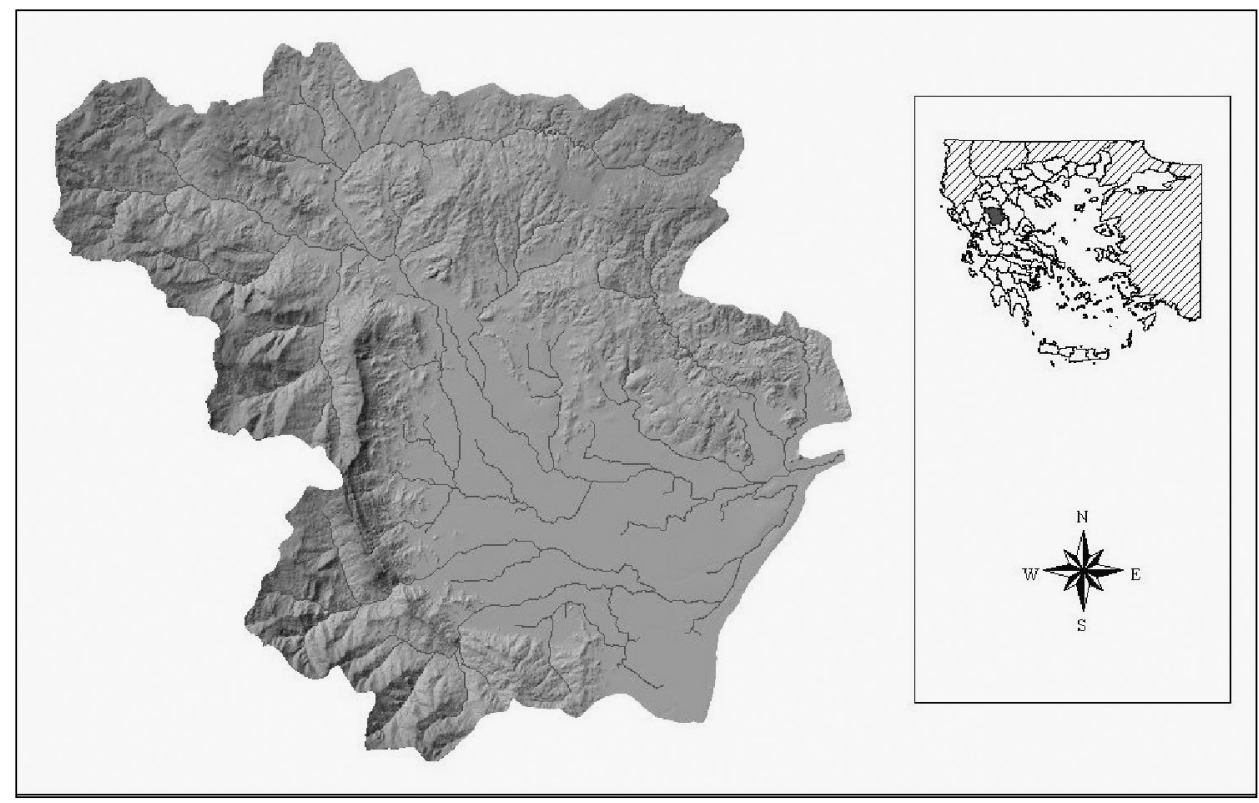

Figure 1. The Ali Efenti basin (Pinios river) in Thessaly, Greece 
outlet of Ali Efenti are available, for the time period from 1970 to 1996 . The streamflow data for the period from $1 / 1970$ to $12 / 1993$ were used for the calibration of the model, while the data from $1 / 1994$ to $12 / 1996$, were obtained later, and were used for model validation.

\section{MODEL IMPLEMENTATION AND SENSITIVITY ANALYSIS}

Model calibration focuses on the detailed representation of the land use data in the watershed, aiming in a more precise simulation of the hydrologic cycle, and in assessing the sensitivity of the model on land use information of varying detail. The present study employs 10 different land uses, whereas previous studies incorporated only 4 different types of land cover (Agriculture, Forest, Urban and Water).

Manual calibration of the model is a complex process requiring experimentation with multiple parameters that affect the precision of the simulation of the water cycle. Regarding the simulation of this particular study, the calibration of the model proved to be quite satisfactory, as indicated by Figure 2. The simulated discharges were compared to the observed on a monthly time step with the use of several indexes, and mainly the Nash \& Sutcliffe coefficient. The Nash \& Sutcliffe coefficient (Nash \& Sutcliffe, 1970) is an estimate of the variation of a time series from another, provided by the equation:

$$
N T D=1-\frac{\sum_{i=1}^{n}\left(Q_{o b s, i}-Q_{s i m, i}\right)^{2}}{\sum_{i=1}^{n}\left(Q_{o b s i}-\bar{Q}_{s i m i}\right)^{2}}
$$

where: $\mathrm{Q}_{\text {sim }}$ is the simulated time series, $\mathrm{Q}_{\mathrm{obs}}$ the observed time series and $\bar{Q}_{\text {sim }}$ the numerical mean for the simulated time series. A Nash \& Sutcliffe coefficient approaching unity indicates that the estimated time series is almost identical to the observed one.

It should be noted that although the model was run for years 1970 to 1993, the first 5 years of simulated output were disregarded in the calibration process, since they are required by the model as a warm-up period. This period is essential for the stabilisation of parameters (e.g groundwater depth), as the results sometimes vary significantly from the observed values. Thus the final calibration period was from April 1975 to December 1993.

The NTD index reached the value of 0.798 , signifying a quite precise calibration. The calibration accuracy was checked by calculating several other indexes, as well. These are the \% difference between the total discharge of the simulated and the observed time series, the Root Mean Square Error (RMSE) and the correlation coefficient of the time series. The results of these tests proved to be quite satisfactory and are summarised in Table 1 , together with the mean observed values of discharge.

Following, the model was validated using the same indexes, for the period of January 1993 to December 1996, giving similar results to those of the calibration. The comparison of the simulated to the observed discharge, for the validation period is presented in Figure 3 and the resulting indexes are summarised in Table 2.

Comparison with a previous calibration of the model, that employed only 4 different types of land uses in the area (Tsotsonis, 2000), highlighted the low sensitivity of the model to the detail of land use data.

\section{LAND USE CHANGE SCENARIOS}

The most significant part of the study was the assessment of the impact that land use changes have on discharge, in terms of quantifying the results from pre-specified scenarios. The process of building a scenario is the creation of a new digital map of land uses, based on the one that depicts the present state of land cover in the watershed. The creation of these maps was made possible with the use of Lademo, a procedure developed by the Potsdam Institute in Germany. The model receives the digital map of the present state as input data and, having taken into account a set of parameters provided by the user, produces an output of the changed land-use map. Because of limitations in the Lademo procedure, and specifically due to the fact that the procedure is "reading" limited land uses (different from the ones imported in the previously described detailed calibration of SWAT), a previous, coarser calibration of the model in the basin was used. This calibration takes into account a set of 4 different land uses: Agricultural Use, Forest, Urban and Water (Tsotsonis, 2000). The following three land use change scenarios were applied: 


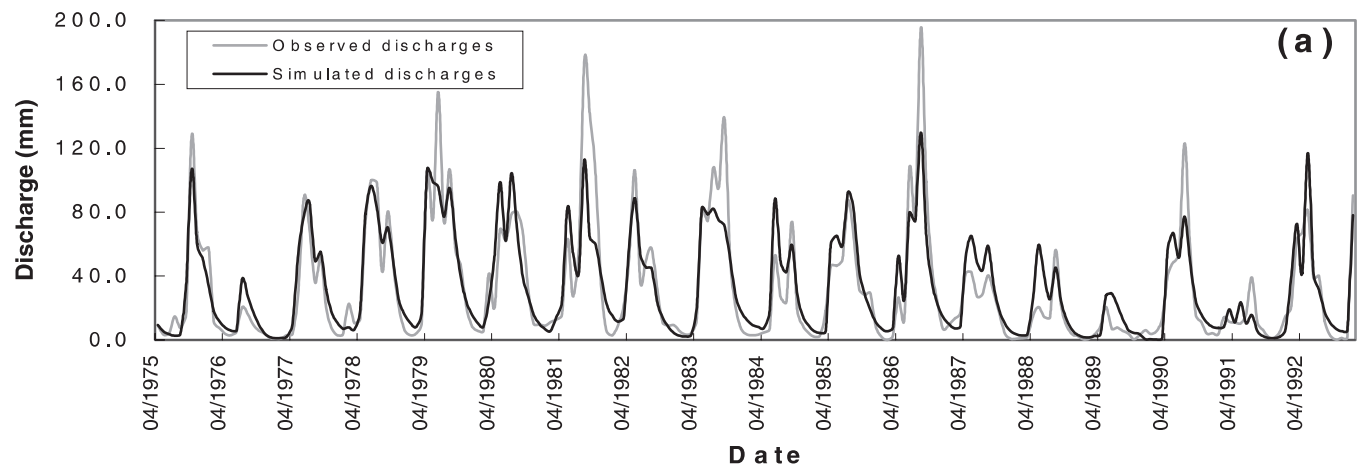

Figure 2. Comparison between simulated and observed discharges in monthly time step for the period 4/1975 12/1993 (Model Calibration)

Table 1. Criteria for examining the accuracy of calibration and mean observed discharge for the time series of 4/1975 - 12/1993.

\begin{tabular}{cccccc}
\hline Index & $\begin{array}{c}\text { Nash \& } \\
\text { Sutcliffe } \\
\text { coefficient }\end{array}$ & $\begin{array}{c}\text { \% difference } \\
\text { of total } \\
\text { discharge }\end{array}$ & $\begin{array}{c}\text { Root Mean } \\
\text { Square Error } \\
(\mathbf{m m})\end{array}$ & $\begin{array}{c}\text { Correlation } \\
\text { Coefficient }\end{array}$ & $\begin{array}{c}\text { Mean } \\
\text { observed } \\
\text { discharge }(\mathbf{m m})\end{array}$ \\
\hline value & 0.798 & 2.96 & 16.30 & 0.90 & 31.59 \\
\hline
\end{tabular}

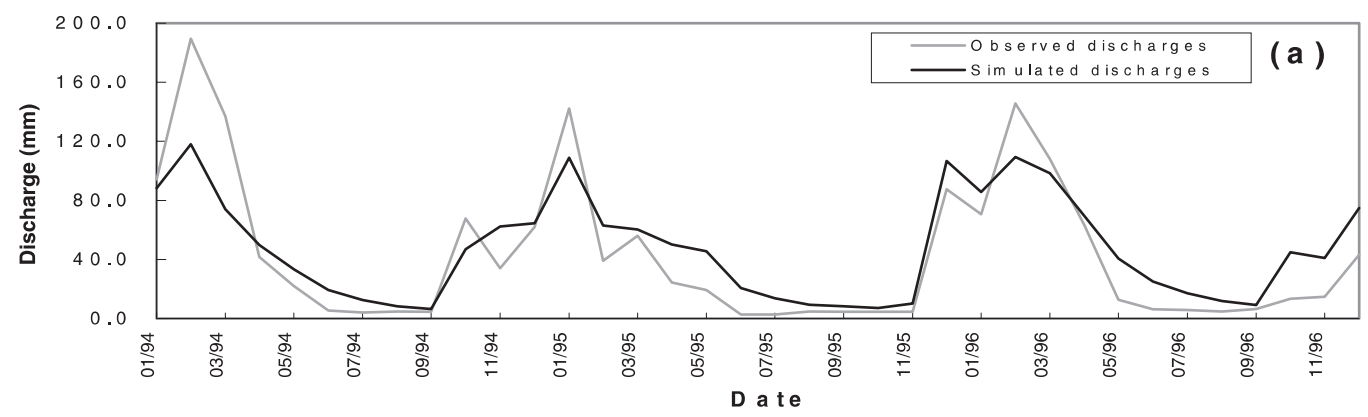

Figure 3. Comparison between simulated and observed discharges in monthly time step for the period 1/1994 12/1996 (Model Validation)

Table 2. Criteria for examining the accuracy of validation and mean observed discharge for the time series of 1/1994 - 12/1996.

\begin{tabular}{cccccc}
\hline Index & $\begin{array}{c}\text { Nash \& } \\
\text { Sutcliffe } \\
\text { coefficient }\end{array}$ & $\begin{array}{c}\text { \% difference } \\
\text { of total } \\
\text { discharge }\end{array}$ & $\begin{array}{c}\text { Root Mean } \\
\text { Square Error } \\
(\mathbf{m m})\end{array}$ & $\begin{array}{c}\text { Correlation } \\
\text { Coefficient }\end{array}$ & $\begin{array}{c}\text { Mean } \\
\text { observed } \\
\text { discharge (mm) }\end{array}$ \\
\hline value & 0.763 & 9.41 & 23.13 & 0.90 & 43.19 \\
\hline
\end{tabular}

Scenario A: Expansion of agricultural land. According to this scenario, the agricultural land area was expanded by a percentage of about $21 \%$, balanced by a decrease of forestry area, while urban and water areas remained intact. The original digital map of the present state is shown in Fig.4a, while the land use pattern after the implementation of this scenario is presented in Fig.4b.
Scenario B: Deforestation of the Trikala subbasin. The Lademo model allows only for the total $(100 \%)$ deforestation of a watershed. Clearly this scenario is unrealistic for application in the whole of the basin, with a total area of around $3000 \mathrm{~km}^{2}$, $57 \%$ of which is occupied by forest. The ability of the SWAT model to partition a basin into subbasins was implemented in this case, by specifying a 
(a)

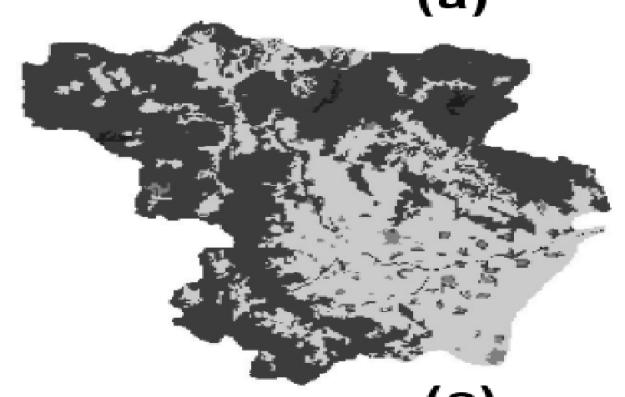

(c)

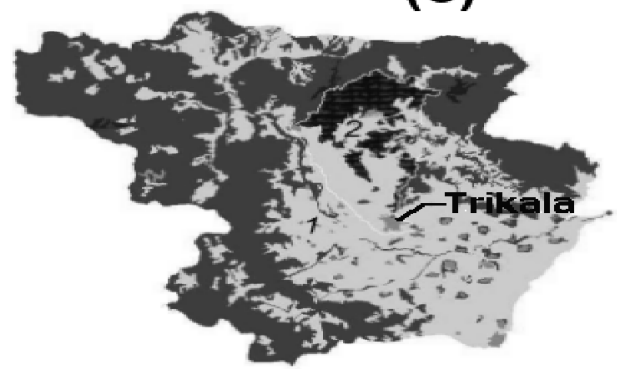

(b)

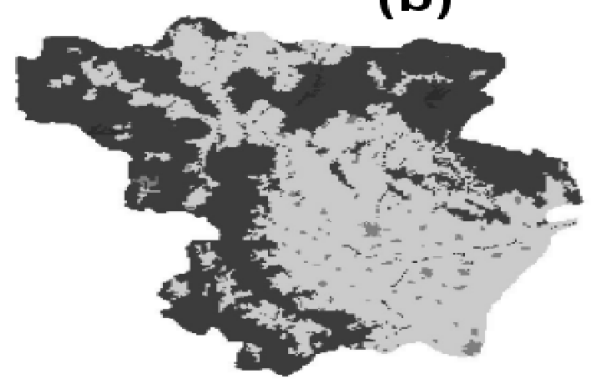

(d)

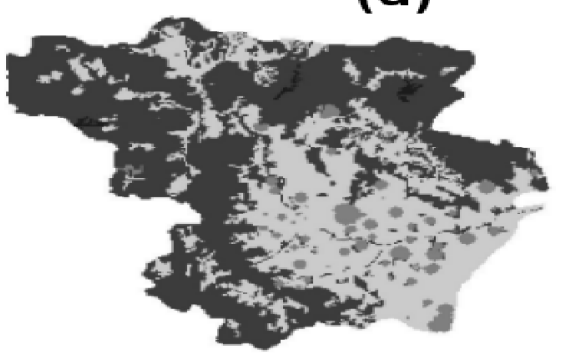

AGRICULTURE

FOREST

URBAN

WATER

BURNT AREAS

Figure 4. Digital maps of land use: (a) Original pattern of land uses, (b) after the expansion of agricultural land, (c) after the deforestation of the Trikala subbasin and (d) after the expansion of urban areas.

point in the stream network, just downstream of the town of Trikala, and directing SWAT to assign a sub-basin to this outlet. The deforestation of this sub-basin, with an area of $270 \mathrm{~km}^{2}$, is more realistic, and therefore this scenario was chosen instead of a $100 \%$ deforestation of the entire basin, as shown in Fig. $4 \mathrm{c}$. The selection of the specific point aimed at the assessment of the variation in the river discharge in the particular branch of the river that passes through a large town of the Thessaly plain.

Scenario C: Expansion of urban areas. This scenario was also applied in the Trikala sub-basin, since the percentage of urban land in this area is greater than the average of the whole watershed, thus intensifying the effects of the change. According to this scenario, depicted in Fig.4d, urban land is expanded by $132 \%$, primarily over the agricultural land and by a smaller percentage over the forestry areas. Although the percentage exceeds $100 \%$, the small proportion of the urban areas in the sub-basin (approx. 3\%) results in a rational amount of land-use change of about 12 $\mathrm{km}^{2}$. The percentages of area change for every land use are presented in Table 3. It should be noted that the values for scenario A refer to the entire watershed of Ali Efenti, while the ones for scenarios B and C correspond to the sub-basin of Trikala.

Table 3. Percentages of land use area change for the three scenarios.

\begin{tabular}{|ccccc|}
\hline & \multicolumn{4}{c|}{ Percentage of area change for every land use \% } \\
\cline { 2 - 5 } Scenario & Urban & Agriculture & Forest & Wetland \\
\hline $\begin{array}{c}\text { A. Expansion of } \\
\text { agricultural land }\end{array}$ & 0.0 & 21.3 & -15.1 & 0.0 \\
B. Deforestation & 0.0 & 0.0 & -100.0 & 0.0 \\
$\begin{array}{c}\text { C. Expansion of } \\
\text { urban land }\end{array}$ & 132.3 & -5.6 & -2.4 & 0.0 \\
\hline
\end{tabular}




\section{RESULTS}

In order to assess the effects of the land use changes suggested by the three scenarios, the new digital maps depicting the land use patterns were imported into SWAT, with the same set of parameters that was used in the original calibration. The execution of the model gave river discharge outputs that correspond to the new land use patterns. These outputs were then compared to the ones of the base run, thus estimating the percentages of discharge change for every scenario. Regarding the first scenario, the output results were the ones simulated in the outlet of Ali Efenti, while for the next two scenarios the corresponding outlet was the one selected just downstream of the town of Trikala. The form of the output charts was more or less anticipated.

Scenario A. Expansion of agricultural land. The mean monthly values for the percentage of change in total discharge for the 24 years of simulation are plotted in Fig.5a. In general, an increase in discharge is observed during wet months and a reduction during dry ones. Increases for wet months are in the range 1-3\%, while during the summer, decreases reach the percentage of $6 \%$ (but refer to a significantly smaller volume of water). This output can be easily interpreted by noting that the CNII value associated to the forestry areas during the calibration is 66 , while the one assigned to the agricultural land is 81 . Consequently, the expansion of agricultural land over forest results in the increase of surface runoff following rainfall events. This expansion also results in the reduction of water infiltrating into the ground and supplying the shallow aquifer. Therefore, discharge during the dry months (which mostly comes from baseflow) decreases, whereas discharge during the wet months increases.

Scenario B. Deforestation of the Trikala subbasin. The results had a pattern similar to the one of the first scenario, with the difference of more intense variations appearing in the percentage of change, as shown in Fig.5b. Increases in discharge reached $23 \%$ of the original value in wet months, while decreases fell to $38 \%$ in July. This can be explained by taking into consideration the big portion of the forestry areas in the sub-basin of
Trikala (44\%). In this section of the basin, the CNII number changed from 66 (Forest) to 84 (Burnt land), resulting in a great increase of the surface runoff and a decrease in base flow.

Scenario C. Expansion of Urban land. The form of changes is similar to the one of the expansion of agricultural land scenario, with some notable variations. In this case, the percentages of change during dry months are significantly lower, as indicated by Fig.5c. This result can be mainly attributed to the type of the applied land-use changes. Baseflow, which is mainly the result of water infiltrating through the forestry areas, undergoes little modification, since only a small portion of the forest area changes in this scenario. In addition, the significant increase of discharge during October is most probably the result of the immediate runoff response of the expanded urban land to the first rainfall events, depending little on the antecedent soil moisture.

\section{CONCLUSIONS}

The method presented for quantifying the effects of land-use change on total runoff for the Ali Efenti watershed in Thessaly combined two advanced models, the hydrological model SWAT and the land use change procedure Lademo. Three different land use change scenarios were applied to the study basin and the discharge outputs were compared to the ones of the base run. All three scenarios gave an increase in discharge during wet months, and a decrease during dry periods. The response of the basin to each scenario can be summarised in the following:

By expanding the agricultural land over forest by $20 \%$, a mean monthly increase in the river discharge of up to $3 \%$ was observed from October to April and a respective reduction from May to September, reaching a maximum of $6 \%$ in July. The deforestation of the Trikala sub-basin that takes place according to scenario B resulted in substantial increases in mean monthly discharge, of around $23 \%$ for wet months, while during the summer, discharge decreased up to $38 \%$.

The final scenario of expansion of urban land by $130 \%$ over agriculture and forest, gave similar results to the ones of the agricultural expansion scenario, with the difference of smaller reductions in discharge during the summer months, and a significant increase of 5\% during October. 
(a)

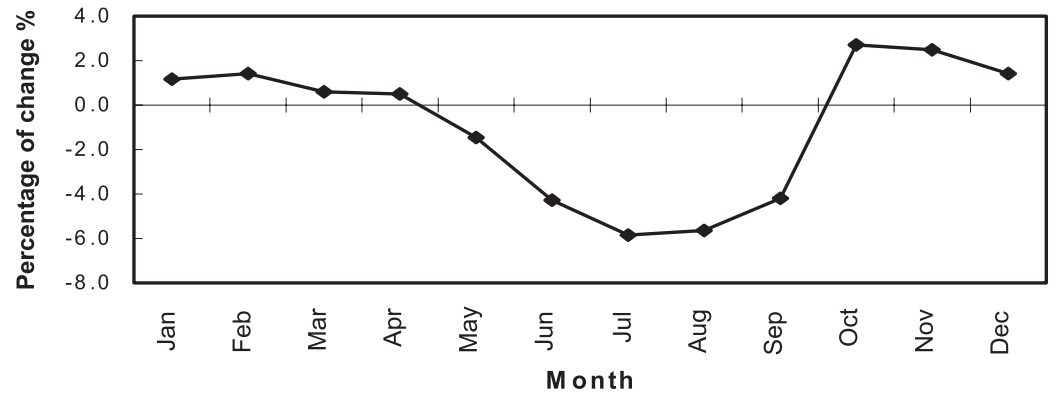

(b)

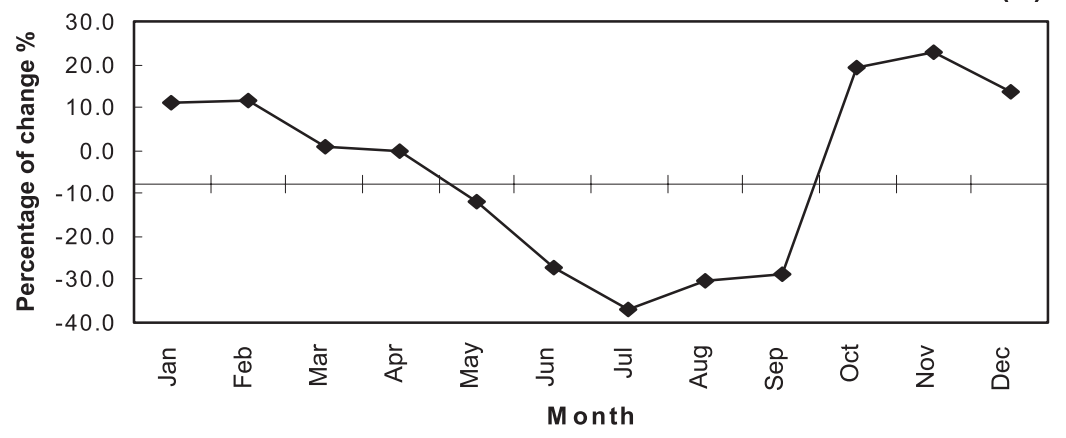

(c)

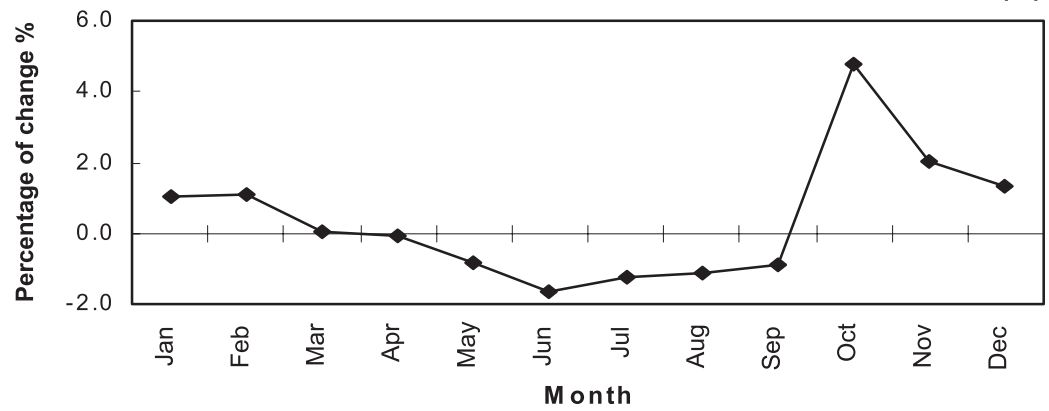

Figure 5. Mean monthly total discharge change (\%) for years 1970-93, corresponding to the scenarios of (a) agricultural expansion, (b) deforestation of Trikala subbasin and (c) urban land expansion.

\section{Acknowledgements}

The work presented is based on research undertaken in the EC funded project EUROTAS
(EUropean River flood Occurence and Total risk ASsessment), funded under the $4^{\text {th }}$ Environment framework ENV 63/846).

\section{REFERENCES}

Arnold, J.G., Williams J.R., Srinivasan R., King, K.W., (1999). Soil and Water Assessment Tool".

Blackland Research Center, Texas Agricultural Experiment Station, (1999). "ArcView Interface for SWAT 98.1". Mimikou M. (1999) "Impact of Climate Change on Water Resources and Water Management. (Key-note Paper 2). Proc. International RIBAMOD Workshop "The Impact of Climate Change on Flooding and Sustainable River Management", (Eds. Balabanis P., Bronstert A., Cassale R. and Samuels P.) EUR 18287, ISBN 92-828-7110-X pp 23-48.

Nash J.E. and Sutcliffe V., (1970). "River flow forecasting through conceptual models, I. A discussion of principles. J. Hydrol. 10, 282-290

Neitsch S.L., Arnold J.G, Williams J.R., (1999). "Soil and Water Assessment Tool, User's Manual". 
Skole D., Tucker C., 1993. "Tropical deforestation and habitat fragmentation in the Amazon: satellite data from 1978 and 1988". Science, 1905-1910.

Tsotsonis G., 2000. "Implementation of the integrated daily model Soil and Water Assessment Tool (SWAT) in Thessaly under conditions of climatic change", in Greek.

Varanou, E., Baltas, E., and Mimikou, M., (2000). Regional Effects of Climate and Land Use Change on the Water Resources and the Risk associated with Flooding. Proc. European Conference on Advances in Flood Research, 1 - 3 November 2000, Potsdam, Germany.

Varanou, E., Gkouvatsou, E., Baltas, E., and Mimikou, M., (2001). Quantity and Quality Integrated Catchment Modelling Under Climate Change. Journal of Hydrologic Engineering, ASCE (submitted for publication).

Verburg P.H., Koning G.H.J, Kok K., Veldkamp A., Fresco L.O. and Bouma J., Wageningen Agricultural University, Netherlands, (1999). "Quantifying the spatial structure of land use change: an integrated approach". 